\title{
NEW BOOKS IN ENGLISH ON CHINESE CORPOREALITY
}

\section{Serguey N. Yakushenkov}

Astrakhan State University. Astrakhan, Russia. Email: shuilong[at]mail.ru

\begin{abstract}
The modern development of China is of great interest to researchers from all over the world. Every year a great number of different monographs on different aspects of this country's history, economy, politics and culture appear. In this analysis of contemporary literature in English we decided to choose several monographs devoted to the issues of corporeality in China. The 20th century proved to be, in a great extent, a decisive period for the development of China. During this period many events took place, but most importantly, China was transformed into something new, becoming a highly developed modern power. These changes also affected the issues of corporeality. A significant role in this was played not only by radical changes in Chinese society, but also by contacts with Western culture and, above all, medicine. In this connection we offer our readers several publications that can be conventionally united by one problem: the transformation of the fundamentals of life. The first monograph by the American anthropologist E. Zhang analyzes the transformation of Chinese attitudes toward male health. Both the Maoist and post-Maoist periods are taken into account. But most importantly, Zhang shows how the changing economic and political model of society is also reflected in Chinese men's attitudes to their health, personal desires and needs.

Another monograph discussed in this review is that of American researcher T. Nakajima, devoted to the creation of a modern system of sanitation and hygiene in Shanghai during the Republican period. In this monograph the author shows how the Chinese approach to the public health system was transformed under the influence of external and internal conditions.
\end{abstract}

\section{Keywords}

China; socio-cultural transformations; hybridity; sexuality; body; health; hygiene; new literature

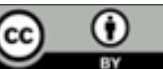

This work is licensed under a Creative Commons «Attribution» 4.0 International License 


\section{НОВЫЕ КНИГИ ПО КИТАЙСКОЙ ТЕЛЕСНОСТИ НА АНГЛИЙСКОМ ЯЗЫКЕ}

\section{Якушенков Сергей Николаевич}

Астраханский государственный университет. Астрахань, Россия. Email: shuilong[at]mail.ru

\section{Аннотация}

Современное развитие Китая вызывает пристальный интерес у исследователей из разных стран мира. Ежегодно появляется огромное количество различных монографий, посвященных разным вопросам истории, экономики, политики и культуры этой страны. В этом анализе современной литературы на английском языке мы решили выбрать несколько монографий, посвященных вопросам телесности в Китае. $\mathrm{XX}$ оказался во многом решающим для развития Китая. В этот период происходило множество событий, но главное, Китай трансформировался в нечто новое, превращаясь в высокоразвитую современную державу. Коснулись эти перемены и вопросов телесности. Значительную роль в этом сыграли не только радикальные перемены в китайском обществе, но и соприкосновение с западной культурой, и прежде всего медициной.

В связи с этим мы предлагаем читателям несколько изданий, которые условно можно объединить одной проблемой: трансформация фундаментальных основ жизни. В первой монографии американского антрополога Э. Чжана анализируется трансформация отношения китайцев к мужскому здоровью. Во внимание принимается как маоистский, так и постмаоистский периоды. Но главное, Чжан показывает, как изменение экономической и политической модели общества отражается и на отношении китайских мужчин к своему здоровью, личностным желаниям и нуждам.

Другой монографией, о которой рассказывается в этом обзоре, является монография американской исследовательницы японского происхождения Т. Накадзимы, посвященная созданию в Шанхае современной системы санитарной службы и гигиены в республиканский период. В этой монографии автор показывает, как под влиянием внешних и внутренних условий трансформировался подход китайцев к системе общественного здоровья.

\section{Ключевые слова}

Китай; социокультурные трансформации; гибридность; сексуальность; телесность; здоровье; гигиена; новая литература 
Социально-экономические и культурные изменения, происходящие в последние годы в Китае, вызывают пристальный интерес среди ученых всего мира. Бурное экономическое развитие влечет за собой и активные культурные преобразования, в процессе которых «традиционная» картина мира подвергается трансформации. Мы специально закавычили термин «традиционная», так как он во многом условен, поскольку вряд ли корректно говорить об этом после экономических, политических и социальных изменений китайского общества в 50-70- гг.. Экономическое развитие Китая после смерти Мао Цзэдуна еще больше ускорило формирование новой картины мира, в которой традиционные институты активно соприкасаются и сливаются с глобалистскими.

Ученые разных стран и разных научных направлений пытаются зафиксировать и осознать эти изменения, выявить их природу и изучить основные тенденции развития. За последние годы вышло множество книг, посвященных проблемам телесности в Китае. Bсе знакомые с происходящим в этой стране невольно удивлялись тому, как менялись китайцы.

Учитывая общественный интерес к различным вопросам, связанным с китайской культурой, мы хотели бы рассказать о новых исследованиях, посвященных проблемам телесности в Китае. Для своего обзора мы выбрали англоязычные монографии разных авторов, посвященные аспектам тела в Китае и опубликованные за последние годы.

Первое исследование, на которое мы хотели бы обратить внимание, как нельзя лучше демонстрирует проблему столкновения традиционного и нового. И на наш взгляд наиболее полно показывает, насколько Китай изменился. Это монография американского социального антрополога Эверетта Юхун Чжана (Everett Yuehong Zhang) «Эпидемия импотенции. Медицина для мужчин и сексуальное желание в современном Китае» (Zhang, 2015).

Академическая судьба Чжан Юхуна (как было бы правильно написать его по китайской традиции) достаточно интересна. Он получил базовое образование в Китае - степень бакалавра в Сычуане, в Чэнду, а степень магистра в Пекине, в Китайской академии социальных наук. Некоторое время работал исследователем в Китайской Академии, но затем отправился в США для написания докторской диссертации. Свою степень Ph.D. по социальной/культурной антропологии он получил в 2003 г. в Университете в Беркли, а затем (2003-2005) продолжил пост-докторские исследования в Гарварде, но уже по медицинской антропологии. Основным предметом исследования доктора Чжана являются различные аспекты китайской телесности. 
В указанной монографии он анализирует феномен «эпидемии» импотенции среди мужчин в Китае, принявшей широкие масштабы в 90-х гг. XX в.. Для исследователя это заболевание не является свидетельством нейрососудистых заболеваний, а представляет собой особый культурный феномен, сформировавшийся в современном Китае в результате серьезных перемен в обществе. С его точки зрения, все эти случаи, как нельзя лучше, характеризуют глубокие социальные и психологические изменения, происходящие в современном Китае. В некоторой степени, осмелимся заявить, что объект его исследования импотенция - всего лишь уловка, своеобразный зачин, позволяющий автору по-новому взглянуть на китайское общество в пореформенную эпоху.

В процессе исследования данной проблемы Э. Чжан опросил 350 мужчин и их партнеров, чтобы выявить самые различные причины этого явления. И в результате анализа этой якобы «эпидемии» сложилась определенная картина, позволившая выявить особые социокультурные предпосылки появления эректильных дисфункций у китайских мужчин. По мнению исследователя эта проблема результат серьезных трансформаций в китайском обществе. За годы, предшествующие периоду реформ, в Китае сложилась система даньвей, представлявшая собой некую производственную единицу, построенную на основе коллективной ответственности (Bray, 2005). По сути, даньвей была своеобразной коммуной, которая объединяла людей не только на основе производства, но и места жительства, регулирования общественной жизни и т.д.. Она регламентировала самые различные стороны повседневной жизни члена этой ячейки, включая семейные отношения, досуг, образование, рождение ребенка и т.д.. Вынужденное раздельное проживание супругов было обычном делом. Мужа или жену могли послать работать в другое место, а супруг не имел возможности жить вместе со своей половиной. Такая практика получила название Liangdi fenju (两地分居) - «в двух разных местах» (Zhang, p. 52).

Хотя зарождение этой системы относят к 50-м гг. ХX в., вместе с тем, во многом подобные социальные институты явились лишь новой формой традиционных общинных отношений, существовавших в сельской местности на протяжении многих веков, а теперь инкорпорированных в городскую среду. Не следует также забывать, что и в СССР были некоторые схожие элементы, когда секретарь парторганизации или партячейка могли разбирать на собраниях частные вопросы семейной жизни своих членов. А члены семьи (как правило, женщины) нередко обращались к секретарю парторганизации за помощью. Партячейка наказывала или поощряла своих членов, выносила предупре- 
ждения, и всячески старалась регламентировать самые различные непроизводственные стороны жизни ее членов.

Мы далеки от того, чтобы полагать, что система даньвей была скопирована с советской партячейки. Однако схожесть некоторых элементов этих систем ставит ряд вопросов об определенных типах развития традиционного общества.

По мнению Э. Чжана, жизнь в подобной ячейке была в значительной мере проникнута духом коллективизма. В ней не было места личностной заинтересованности, проявлению индивидуализма и т.д..

В этот период, если у мужчин и возникали, подобные проблемы, то было не принято обращаться к врачу. Вместе с тем, уже тогда, как удалось выяснить Чжану, очень многие китайские мужчины страдали от импотенции, которая чаще всего являлась результатом давления (эмоционального, физического) со стороны китайского общества на так называемых классовых врагов: зажиточных крестьян, буржуазных элементов и т.д.. Учитывая то, как китайские мужчины относятся к своей потенции, насколько они зациклены (конечно, не только они) на своих сексуальных способностях, появление эректильной дисфункции у лиц, подвергшихся гонениям и репрессиям, воспринималось как двойная трагедия, ощущение которой жертва вынуждена была носить внутри.

Конечно, многие могут сказать, что в выводе, к которому приходит Э. Чжан, нет ничего нового, так как современной медицине давно известно, что этиология подобных сексуальных расстройств кроется в психологических проблемах пациента. Естественно, что то давление, которое общество оказывало на некоторых индивидуумов в период маоизма, не могло не сказаться на их состоянии.

Но было бы неверно полагать, что основной целью исследования Чжана было выявление причин эректильных дисфункций в период 50-70-х гг.. Исследования автора показали, что социально-психологическое давление общества на индивидуума не только не снизилось в 90-е гг., но возможно стало еще сильнее. Причины этого в постоянных стрессовых ситуациях, в которых оказывается индивид: давление со стороны начальства, экономические сложности, стремление закрепить свой социальный статус и т.д..

Однако теперь мужчины не стеснялись обращаться в клиники, рассказывая врачам о своих проблемах. В этот период в Китае даже возникает особое направление в медицине, посвященное «мужским проблемам» - наньке (досл. «мужская медицина») (pp. 29-50). Сам факт появления подобного направления свидетельствует о серьезных переменах в китайском обществе. 
Следует понимать, что данное исследование, несмотря на, казалось бы, медицинскую проблематику, имеет отношение не к вопросам медицины или медицинской антропологии, а освещает важные вопросы китайской культуры. На основании множества свидетельств и исследованиях других ученых Э. Чжан приходит к выводу, что с 90-е гг. происходит важнейший сдвиг в сознании китайцев. Индивидуум начинает не только осознавать свои права на сексуальные желания, но и бороться за них. Значимость этой монографии, которая во многом основывается на исследовании, проведенном автором при работе диссертацией, очень хорошо демонстрирует те глубинные изменения, которые претерпевает китайское общество.

Интересны замечания автора и по поводу отношения китайцев к различным современным западным лекарствам для повышения потенции (типа виагры), взгляд на которые в Китае серьезнейшим образом разнится с западными странами.

Значительная часть данной монографии анализирует современное отношение к потенции/импотенции в рамках западной и китайской медицины. На наш взгляд, эта часть работы особенно интересна и глубоко проработана. Наньке, возникнув на волне интереса китайцев к личностным проблемам и желаниям, впитала в себя в самые различные подходы, став для многих путеводной звездой личностного благополучия.

Следует понимать, что наньке в Китае превратилось не только в особое направление медицины, но и стало своеобразной концепцией жизни. И в этом вопросе наньке ориентируется не только на западную науку, но и на традиционную медицину, часто делающую акцент не сколько на лечение болезни, сколько на предотвращение ее. Bce, кто хоть раз побывал в Китае, видели во всех парках огромное количество стариков, занимающихся физическими упражнениями - «пестованием жизненной энергии».

В этом стремлении поддержания «жизненной энергии» мужская потенция занимает важное место, указывая на состояние здоровья человека, а точнее на работу его внутренних органов, в первую очередь печени и почек. В рамках традиционных подходов, базирующихся на китайской медицине, потеря семени ведет к потере жизненной энергии, что не очень хорошо сказывается на здоровье мужчины.

Все это входит в противоречие с личностными желаниями человека, его стремлениями к регулярной и полноценной сексуальной жизни. Усилившаяся маскулинизация китайского общества серьезнейшим образом отражается на культуре поведения. В связи с этим 


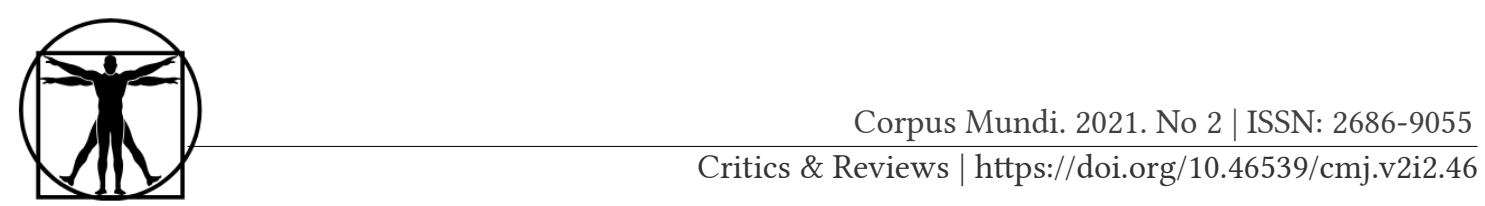

сексуальные успехи и способность пить много спиртного оказываются знаковыми маркерами «настоящего мужчины».

Bсе это в какой-то степени входит в противоречие с традиционными подходами (не путать с моральными ценностями), базирующимися на принципах сохранении семени (цзин/цзинйе). Исследование Э. Чжана - это нескончаемая череда личных биографий, в которых как в зеркале отражается вся история Китая во второй половине XX- нач. XXI BB..

Будучи специалистом как в социальной (культурной) и медицинской антропологии, Э. Чжан рисует широкую панораму происходящих в Китае перемен, показывая как традиции сталкиваются, соприкасаются и смешиваются с современными тенденциями жизни.

Как нам кажется, данная монография полезна для самого широкого круга специалистов, интересующихся как историей китайской медицины, так и китайской культурой.

Следующая монография, о которой мы бы хотели поговорить это «Тело, общество и нация. Создание общественного здоровья и городской культуры в Шанхае» американской исследовательницы Тиэко Накадзимы.

В некотором роде монография Накадзимы посвящена схожим проблемам истории Китая - вопросам трансформации телесности в переходные периоды. Правда, в данном случае в качестве основного периода был выбран республиканский, а пространственная привязка сделана к Шанхаю. Вместе с тем, как и в случае с исследованием Чжана, в этой работе анализируются процессы слияния китайских подходов к телесности и гигиене с западными. Именно поэтому, как нам кажется, автор и выбрала его для своего исследования, где создалась особая ситуация с экстерриториальными европейскими поселениями. Именно в подобных городах происходило слияние двух подходов к вопросу личностного и общественного здоровья, гигиены и т.д.. В некотором роде данная монография является продолжением исследования К. Л. МакФерсон, анализировавшей возникновение и развитие вопросов здравоохранения в международных поселениях в Шанхае (MacPherson, 1987). В свою очередь Т. Накадзима рисует довольно-таки полную картину модернизации здравоохранения на территории Шанхая, под управлением республиканского правительства. Все это представляется особенно интересным в силу двух причин: гибридный характер развития культуры в Шанхае в этот период и возможность сравнить полученный материал с другими исследованиями, в частности со схожим исследованием Р. Рогаски (Rogaski, 2014), также анализировавшей модернизацию здравоохранения в Китае в дого- 
ворных портах, в частности на территории Тяньцзиня, расположенного на берегу Бохайского залива.

Все это позволяет выявить определенные общие тенденции, свойственные для подобных гибридных территорий. Да и само исследование Накадзимы представляет собой сплав разных уровней проблемы, что в общем-то вытекает из самого названия монографии: «Тело, общество, нация». Другими словами, Накадзима рассматривает «гигиеническую модернизацию» в Шанхае сразу в трех аспектах: личностном (индивидуальное тело), социально-политическом (общество, управление и т.д.) и социально-культурном (идентичность). Вместе с тем, следует отметить, что автор старается избегать жесткой дихотомии (Восток/Запад, традиция/модернизация и т.д.), что дает возможность увидеть различные аспекты этого явления. Но это не удивительно, будучи этнической японкой с западным образованием, Тиеко Накадзима может не следовать какой-то одной культурной модели, являясь чем-то большим, чем определенная национальная принадлежность. Знание множества языков дало ей возможность поднять самый широкий круг источников, как архивных, так и различных иных нарративов (газетных и журнальных публикаций, биографий и т.д.). Ею привлекались самые различные материалы: британские, китайские и даже японские.

И все же автору сложно было избежать определенной дихотомии, ведь Шанхай в республиканский период не представлял собой единого целого: три различных района, с разными укладами, разным уровнем жизни и с разной культурой. Иностранцы, проживавшие в Шанхае в этот период, рассматривали китайскую часть города как сосредоточие болезней, заразы, и нечистот. Быстрый рост иностранных поселений, богатевших на процветающей торговле, способствовал притоку в Шанхай китайцев, нанимавшихся обслуживать иностранцев. Все это превращало отдельные части города в антисанитарные трущобы. Нередко высокие стандарты гигиены, навязываемые иностранцами китайцам, воспринимались как колониализм и расизм (р. 106).

Вместе с тем, китайская элита, жившая на территории иностранных поселений, остро и в целом положительно реагировала на нововведения, стараясь подражать европейцам в вопросах гигиены, хотя не все относились к ним так уж однозначно.

Именно под влиянием организации здравоохранения на территориях иностранных поселений китайские власти начали создавать свою систему здравоохранения. Это касалось сразу двух аспектов: создание клиник и госпиталей, совмещавших западные и китайские традиции, 
и формирование институтов контроля и управления здравоохранением в масштабах города.

Первая глава монографии посвящена именно созданию больниц современного типа. Накадзима рисует довольно-таки подробную картину формирования этого важнейшего института современного общества.

Вторая глава посвящена созданию административных институтов - Шанхайского департамента общественного здоровья (PDH). Именно благодаря стараниям этого департамента удалось поднять стандарты качества потребляемой воды и пищевых продуктов, что благоприятно сказывалось на здоровье населения.

Примечательно, что руководство PDH пыталось проводить очень взвешенную политику не только в отношении китайской части города, но и иностранных поселений. Так оно не только ввело принципы лицензирования хлебобулочных и мясных изделий на китайской территории, но и предложила свои условия для лицензирования китайских продавцов, работавших на территории иностранных поселений. И хотя администрация иностранных поселений не приняла это предложение, сам факт уже говорит о том, что китайская администрация осознавала важность подобных действий. Западная администрация отвергла это предложение не потому, что не нуждалась в подобной деятельности, а потому что британские инспектора нашли уровень санитарного состояния лицензированных предприятий недостаточным.

Но даже начальные меры по улучшению санитарного состояния города дали положительные результаты, снизив процент желудочнокишечных заболеваний жителей города.

Третья глава монографии посвящена такому важнейшему аспекту здравоохранения, как пропаганда санитарных и гигиенических норм. Автор рассматривает самые различные методы и механизмы этой пропаганды: их можно назвать воспитательными и образовательными. Выставки, лекции, наглядная агитация, вовлечение общественности в санитарные мероприятия и многие другие виды деятельности стали важнейшей частью, так называемых, гигиенических компаний (вейшен юньдун). Администрации удалось привлечь огромное количество жителей для уборки города, организовать множество лекций, на которых объяснялась важность гигиены, правил поведения в обществе и многое другое.

На наш взгляд, особого упоминания заслуживает и четвертая глава этой монографии. Она показывает, как достижения западной цивилизации активно входили в коммерческую культуру Китая. По мнению 
автора, именно деятельность некоторых китайских предпринимателей сделала настоящий прорыв по пути продвижения санитарных норм и гигиенических правил. Два талантливых предпринимателя - Фан Есяня и Чэнь Диэсяня - смогли наладить выпуск китайских продуктов бытовой химии. Действуя в коммерческих интересах, они смогли наладить не только само производство, но с помощью действенной рекламы, активно продвигали свою продукцию в народные массы. Будучи самоучками, они изучали элементарную химию, учились у западных конкурентов, приглашали высокооплачиваемых иностранных специалистов и т.д., стараясь развивать свои компании.

Делая акцент на деятельности этих успешных бизнесменов, на их личных биография, автор пытается нарисовать самую широкую картину развития санитарии (гигиенической модернизации) в Китае.

Конечно, не со всеми выводами автора можно согласиться. Вероятно, ряд заявлений может вызвать крайне негативную реакцию со стороны китайских властей и общественности, особенно касательно положительных действий японских оккупационных властей по развитию санитарии и здравоохранения в городе. Хотя подобные заявления автор сопровождает замечаниями, что все действия колониальной администрации по улучшению санитарии в городе и здоровья граждан делались не ради китайцев, а ради самих европейцев, американцев или японцев, живших на этой территории.

Но как бы то ни было, сложно отрицать и тот факт, что в конечном итоге подобные действия приводили и к улучшению жизни самих китайцев, перенимавших лучшие традиции и творчески инкорпорируя их в свою жизнь.

В любом случае, данное исследование представляет богатый материал для изучения развития Китая в первой половине XX в.. Интересен и опыт формирования гибридных социумов. Результатом этого затянувшегося на более чем столетие эксперимента стало современное развитие Шанхая, представляющего собой передовой высокоразвитый мегаполис.

И, наконец, всем, кого заинтересовала данная проблематика, мы можем порекомендовать еще одно исследование, которое в той или иной мере касается этого же вопроса. Это монография британской исследовательницы Изабеллы Джексон «Формируя современный Шанхай». Как и предыдущие авторы, И. Джексон внимательно подходит к изучению гибридного общества. В ее монографии есть и глава 4, посвященная вопросам формирования общественного здоровья и гигиены в Шанхае (Jackson, 2017, pp. 164-201). 
Интересны и некоторые другие исследования И. Джексон, посвященные взаимовлиянию китайского и британского миров, особенно через призму использования индийцев (сикхов) в качестве полицейских в Шанхае. Но это совсем иная история.

В своем обзоре мы коснулись лишь нескольких книг по отдельным темам. За последние годы вышло много и других исследований, о которых мы расскажем в следующих номерах нашего журнала.

\section{Список литературы}

Bray, D. (2005). Social Space and Governance in Urban China. The Danwei System from Origins to Reform. Palo Alto: Stanford University Press.

Jackson, I. (2017). Shaping Modern Shanghai: Colonialism in China's Global City. Cambridge: Cambridge University Press.

MacPherson, K. L. (1987). A Wilderness of Marshes: The Origins of Public Health in Shanghai, 1843-1893. Oxford: Oxford University Press.

Nakajima, C. (2018). Body, Society, and Nation: The Creation of Public Health and Urban Culture in Shanghai. Cambridge, Mass.: Harvard University Press.

Rogaski, R. (2014). Hygienic Modernity: Meanings of Health and Disease in Treaty-Port China. Berkeley: University of California Press.

Zhang, E. Y. (2015). The Impotence Epidemic: Men's Medicine and Sexual Desire in Contemporary China. Durham; London: Duke University Press.

\section{References}

Bray, D. (2005). Social Space and Governance in Urban China. The Danwei System from Origins to Reform. Palo Alto: Stanford University Press.

Jackson, I. (2017). Shaping Modern Shanghai: Colonialism in China's Global City. Cambridge: Cambridge University Press.

MacPherson, K. L. (1987). A Wilderness of Marshes: The Origins of Public Health in Shanghai, 1843-1893. Oxford: Oxford University Press.

Nakajima, C. (2018). Body, Society, and Nation: The Creation of Public Health and Urban Culture in Shanghai. Cambridge, Mass.: Harvard University Press.

Rogaski, R. (2014). Hygienic Modernity: Meanings of Health and Disease in Treaty-Port China. Berkeley: University of California Press.

Zhang, E. Y. (2015). The Impotence Epidemic: Men's Medicine and Sexual Desire in Contemporary China. Durham; London: Duke University Press. 